\title{
Characterization of Narcotics of Vegetal Origin by Their Content of Various Elements Determined by Atomic Absorption Spectrophotometry with Sampling in Carbonaceous Slurry
}

\author{
F. Fagioli*, C. Locatelli*, L. Scanavini*, S. Landi** \\ and G. Berti DonINI*** \\ * Laboratory of Analytical Chemistry, Department of Chemistry, University of Ferrara \\ ** Laboratory of Agricultural Chemistry, Department of Chemistry, University of Ferrara, \\ Via L. Borsari 46, 44100 Ferrara, Italy \\ ***Institute of Legal Medicine and Insurance Medicine, University of Ferrara, \\ Via Fossato di Mortara 64/B, 44100 Ferrara, Italy
}

\begin{abstract}
The $\mathrm{Na}, \mathrm{K}, \mathrm{Ca}, \mathrm{Mg}, \mathrm{Fe}, \mathrm{Cu}, \mathrm{Mn}$ and $\mathrm{Zn}$ contents of hashish batches in judicial seizing were determined in order to confirm, once again, the reliability (expressed by precision and accuracy) of the "Carbonaceous Slurry" as pretreatment of complex organic matrices prior to analysis. The analysis of pressed cakes of five different batches also served to prove the homogeneity of the analytical data in a statistical sense both related to one cake (relative standard deviation) and to different cakes of one batch (t-test) as well as to determine the equality or the nonequality of the batches on the basis of the analytical data (variance analysis, Duncan-test).
\end{abstract}

Keywords Narcotics, element analysis, carbonaceous slurry, atomic absorption spectroscopy

The quantitative determination of elements in solid organic matter of biological origin requires, at first, the mineralization of the sample, i.e. the complete destruction of the organic substances and the solubilization of the elements to be determined. The most often used pretreatments of those matrices are the following: a) ashing in oxygen plasma, b) dry ashing, c) wet mineralization, d) wet mineralization in autoclave.

Recently we proposed a new method based on the preparation of "Carbonaceous Slurry". The reliability of the latter, in terms of accuracy and precision, has been examined in the case of the determination of $\mathrm{Ca}$, $\mathrm{Mg}, \mathrm{K}, \mathrm{Mn}, \mathrm{Zn}, \mathrm{Cu}, \mathrm{Fe}, \mathrm{Pb}, \mathrm{Cd}$ in organic matrices of different compositions, which required special attention in the samples preparation. ${ }^{1}$ These determinations either employed the flame atomic absorption spectroscopy (FAAS) $)^{2,3}$ or the graphite-tube furnace atomic absorption spectroscopy (GTFAAS). ${ }^{4}$

The present work is intended both to confirm the reliability of the "Carbonaceous Slurry" technique in the case of a complex solid matrix of plant origin and to prove the equality or the non-equality of batches of narcotics by determining of a certain number of characteristic elements. The latter topic is a part of a general problem concerning the identification of the origin of the narcotics for sale on the street. An attempt to solve the latter problem has already been carried out by means of neutron activation. ${ }^{5}$

The $\mathrm{Na}, \mathrm{K}, \mathrm{Ca}, \mathrm{Mg}, \mathrm{Mn}, \mathrm{Fe}, \mathrm{Zn}$ and $\mathrm{Cu}$ contents of five batches of Cannabis Sativa Indica resin seized by the relevant authorities were analyzed.

\section{Experimental}

\section{Instrumentation}

A Perkin Elmer Model 603 atomic absorption spectrophotometer equipped with a deuterium background corrector and single-element intensitron cathode lamps was used in the measurements. A premix design $10 \mathrm{~cm}$ long titanium single-slot burner head was used with acetylene fuel and air as the oxidant. The instrument settings recommended by the manufacturer were employed. ${ }^{6}$ The sample pretreatment was performed in a programmable aluminium block digestor. Dilutions were carried out using Gilsonmicropipets.

\section{Reagents and standard solutions}

Carbonaceous slurries of hashish samples were prepared in 96\% sulphuric acid (Suprapure E. Merck). Standard solutions were prepared using BDH stock 
solutions containing $1000 \mathrm{mg} / 1$ of each element. Dilutions were made with deionized water.

\section{Description of material and sampling}

The five batches of hashish examined were of unknown geographical origin and were seized by the authorities at various localities of the Italian peninsula at different time. The batches consisted of identical compact pressed cakes which had equal weight, form and method of packing within one batch, but the cakes of different batches differed in one or another of these characteristics.

Sampling was carried out using a tool constructed in our laboratories consisting of a stainless steel tube having a saw-toothed edge. The sampler was introduced in the material with rotatory movement and the sample was collected from the inside of the tube.

Two cakes each were sampled from batches A and B in order to obtain information of the variation of the inorganic composition of the material in the interior of a cake as well as in different cakes.

Separate samples were taken at four different points of each of two cakes. The samples amounted to 4 per cent of the total weight of the cake, i.e. each sample was equivalent to 1 per cent of the weight of a cake. Finally samples were taken from at least three cakes of each batch in the manner described above and the samples taken from each cake were thoroughly mixed in order to obtain a sample characteristic of each cake.

\section{Preparation of the samples}

Samples were deep-frozen at $-10^{\circ} \mathrm{C}$ for one hour and then ground in a blade-type grinder. An amount of $0.25 \mathrm{~g}$ of the powder was dried at $85^{\circ} \mathrm{C}$ for 24 hours and weighed in graduated pyrex digestion tubes of a volume of $25 \mathrm{ml}$. Concentrated sulphuric acid $(2.5 \mathrm{ml})$ was added to the tubes and stirred in a vortex stirrer. The tubes were heated in a heating block at a rate of 3 to $4^{\circ} \mathrm{C} / \mathrm{min}$ to $320^{\circ} \mathrm{C}$ and kept at the latter temperature for one hour. The tubes were filled up to the mark with deionized water after cooling.

Blank tests were done in an identical manner.

\section{Data-processing \\ Experimental data were processed with a Digital MINC-11 computer.}

\section{Analytical procedure}

The carbonaceous slurries were diluted in order to adjust the concentration of the element to be determined in the range of linearity of the respective analytical calibration function. Sodium and potassium were determined in the presence of 0.2 volume per cent of caesium while in the determination of calcium and magnesium 0.5 volume per cent of lanthanum was added.

The samples were stirred in a vortex for two minutes just before atomization. The absorbance measurements (average of five readings) were corrected for the blank value. This practice was adopted because the deuterium background corrector did not elminate completely the absorbance of the carbonaceous slurry blank. This incomplete blank correction can probably be attributed to the presence of an irregular background. ${ }^{7}$

All the elements were determined using the respective analytical calibration functions calculated on the basis of calibration data obtained in the measurement of aqueous standards. This procedure was presumed to be correct as the slope of the analytical calibration function (analytical sensitivity $s$ ) obtained by the standard addition method in the carbonaceous slurry was found to be practically equal to that measured in aqueous solutions. Thus interference from the matrix was assumed to be negligible.

\section{Results and Discussion}

The aim of the present paper was both to once again confirm the reliability (expressed by precision and accuracy) of the "Carbonaceous Slurry" as pretreatment of complex organic matrices prior to analysis and to prove the equality, or the non-equality, of batches of narcotics by the determination of a certain number of characteristic elements.

For all the elements considered, the reliability of the "Carbonaceous Slurry" technique in terms of analysis accuracy of complex solid organic materials was reconfirmed by the recovery tests performed with samples of batches A and B. These tests were made by adding the elements to the samples in vegetable product form with a certified mineral composition such as Orchard Leaves SRM 1571. ${ }^{3}$ The results covered the range from 94 to 105 per cent and indicated the good accuracy of the method which is beyond doubt suitable for all kinds of practical applications, as also demonstrated in previous papers regarding different organic matrices. ${ }^{2-4}$

Finally, the precision of the method, expressed as relative standard deviation $s_{\mathrm{r}}$, proved to be excellent ( $s_{\mathrm{r}}$ less than $5 \%$ in all cases).

Table 1 shows the results of $\mathrm{Na}, \mathrm{K}, \mathrm{Ca}, \mathrm{Mg}, \mathrm{Fe}, \mathrm{Cu}$, $\mathrm{Mn}$ and $\mathrm{Zn}$ determinations in seized hashish samples in terms of the 95 per cent confidence interval for the mean as well as relative standard deviation $s_{\mathrm{r}}$.

The first problem consisted of determining the analytical data dispersion for each metal referring to one cake as well as of those relating to several cakes of the same batch. The relative standard deviation $s_{\mathrm{r}}$ of the data related to the four separate samples of each cake can be assumed to indicate the analytical data dispersion within the same cake. It is apparent that, for both batches A and B, $s_{\mathrm{r}}$ was better than $3 \%$ except in some cases $($ e.g. $\mathrm{Cu})$.

The second problem consisted of verifying the analytical data dispersion referring to different cakes of the same batch. Thus, once performed the $F$-test, 
Table 1 Analytical results of $\mathrm{Na}, \mathrm{K}, \mathrm{Ca}, \mathrm{Mg}, \mathrm{Fe}, \mathrm{Cu}, \mathrm{Mn}$ and $\mathrm{Zn}$ determinations in hashish samples of two batches seized by the authorities

\begin{tabular}{|c|c|c|c|c|c|}
\hline & & \multicolumn{2}{|c|}{ Batch A } & \multicolumn{2}{|c|}{ Batch B } \\
\hline & & Cake $\mathbf{A}_{1}$ & Cake $\mathbf{A}_{2}$ & Cake $B_{1}$ & Cake $\mathbf{B}_{2}$ \\
\hline & \multicolumn{2}{|c|}{ No. of samples 4} & 4 & 4 & 4 \\
\hline $\mathbf{N a}$ & $\bar{c}, \%$ & $0.531 \pm 0.026$ & $0.553 \pm 0.014$ & $0.027 \pm 0.001$ & $0.028 \pm 0.002$ \\
\hline & $s_{\mathbf{r}}, \%$ & 3.0 & 1.6 & 2.9 & 3.3 \\
\hline $\mathbf{K}$ & $\vec{c}, \%$ & $2.03 \pm 0.08$ & $1.98 \pm 0.09$ & $0.207 \pm 0.013$ & $0.203 \pm 0.009$ \\
\hline & $s_{\mathrm{r}}, \%$ & 2.5 & 2.8 & 3.9 & 2.6 \\
\hline $\mathrm{Ca}$. & $\begin{array}{l}\bar{c}, \% \\
s_{\mathbf{r}}, \%\end{array}$ & $\begin{array}{c}6.53 \pm 0.31 \\
3.0\end{array}$ & $\begin{array}{c}6.37 \pm 0.20 \\
2.0\end{array}$ & $\begin{array}{c}3.68 \pm 0.27 \\
4.6\end{array}$ & $\begin{array}{c}3.71 \pm 0.25 \\
4.2\end{array}$ \\
\hline Mg & $\begin{array}{l}\bar{c}, \% \\
s_{\mathbf{r}}, \%\end{array}$ & $\begin{array}{c}0.676 \pm 0.012 \\
0.9\end{array}$ & $\begin{array}{c}0.657 \pm 0.030 \\
2.8\end{array}$ & $\begin{array}{c}0.415 \pm 0.020 \\
3.0\end{array}$ & $\begin{array}{c}0.406 \pm 0.012 \\
1.9\end{array}$ \\
\hline $\mathbf{F e}$ & $\begin{array}{l}\bar{c}, \% \\
s_{\mathrm{r}}, \%\end{array}$ & $\begin{array}{c}0.327 \pm 0.010 \\
2.0\end{array}$ & $\begin{array}{c}0.325 \pm 0.004 \\
0.7\end{array}$ & $\begin{array}{c}0.537 \pm 0.033 \\
3.9\end{array}$ & $\begin{array}{c}0.556 \pm 0.002 \\
2.5\end{array}$ \\
\hline $\mathbf{C u}$ & $\bar{c} / \mu \mathrm{g} \mathrm{g}^{-1}$ & $11.4 \pm 1.6$ & $10.7 \pm 1.6$ & $8.78 \pm 0.38$ & $8.78 \pm 0.38$ \\
\hline Mn & $\begin{array}{l}s_{\mathrm{r}}, \% \\
\bar{c} / 4 \mathrm{~g}-\mathrm{g}\end{array}$ & $\begin{array}{c}8.7 \\
570 \pm 20\end{array}$ & $\begin{array}{c}9.3 \\
570 \pm 10\end{array}$ & $\begin{array}{c}2.7 \\
48.3 \pm 2.2\end{array}$ & $\begin{array}{c}2.7 \\
48.8 \pm 2.1\end{array}$ \\
\hline $\mathbf{Z n}$ & $\begin{array}{l}s_{\mathrm{r}}, \% \\
\bar{c} / \mu \mathrm{g} \mathrm{g}^{-1} \\
s_{\mathrm{r}}, \%\end{array}$ & $\begin{array}{c}2.3 \\
44.3 \pm 2.2 \\
3.2\end{array}$ & $\begin{array}{c}0.8 \\
42.8 \pm 2.0 \\
3.0\end{array}$ & $\begin{array}{c}2.9 \\
150 \pm 10 \\
2.5\end{array}$ & $\begin{array}{c}2.8 \\
140 \pm 10 \\
2.2\end{array}$ \\
\hline
\end{tabular}

Table 2 Analytical results of $\mathrm{Na}, \mathrm{K}, \mathrm{Ca}, \mathrm{Mg}, \mathrm{Fe}, \mathrm{Cu}, \mathrm{Mn}$ and $\mathrm{Zn}$ determinations in hashish samples seized by the authorities

\begin{tabular}{|c|c|c|c|c|c|c|}
\hline & & \multicolumn{5}{|c|}{ Batch } \\
\hline & & $\mathbf{A}$ & B & $\mathbf{C}$ & $\mathbf{D}$ & $\mathbf{E}$ \\
\hline & \multicolumn{2}{|c|}{ No. of cakes 3} & 3 & 3 & 3 & 3 \\
\hline $\mathrm{Na}$ & $\begin{array}{l}\bar{c}, \% \\
s_{\mathrm{r}}, \%\end{array}$ & $\begin{array}{c}0.553 \pm 0.029 \\
2.08\end{array}$ & $\begin{array}{c}0.0278 \pm 0.0010 \\
1.57\end{array}$ & $\begin{array}{c}0.131 \pm 0.007 \\
2.3\end{array}$ & $\begin{array}{c}0.054 \pm 0.002 \\
1.2\end{array}$ & $\begin{array}{c}0.098 \pm 0.001 \\
0.6\end{array}$ \\
\hline $\mathbf{K}$ & $\bar{c}, \%$ & $\begin{array}{c}2.01 \pm 0.11 \\
2.24\end{array}$ & $\begin{array}{c}0.0208 \pm 0.0026 \\
5.1\end{array}$ & $\begin{array}{c}1.13 \pm 0.06 \\
2.0\end{array}$ & $\begin{array}{c}1.34 \pm 0.01 \\
0.4\end{array}$ & $\begin{array}{c}1.19 \pm 0.14 \\
4.5\end{array}$ \\
\hline $\mathbf{C a}$ & $\begin{array}{l}\bar{c}, \% \\
s_{\mathbf{T}}, \%\end{array}$ & $\begin{array}{c}6.39 \pm 0.35 \\
2.23\end{array}$ & $\begin{array}{c}3.65 \pm 0.32 \\
3.60\end{array}$ & $\begin{array}{c}4.39 \pm 0.20 \\
1.8\end{array}$ & $\begin{array}{c}1.42 \pm 0.01 \\
0.3\end{array}$ & $\begin{array}{c}2.01 \pm 0.05 \\
1.0\end{array}$ \\
\hline $\mathbf{M g}$ & $\begin{array}{l}\bar{c}, \% \\
s_{\mathbf{T}}, \%\end{array}$ & $\begin{array}{c}0.658 \pm 0.040 \\
2.46\end{array}$ & $\begin{array}{c}0.411 \pm 0.001 \\
1.14\end{array}$ & $\begin{array}{c}0.578 \pm 0.046 \\
3.2\end{array}$ & $\begin{array}{c}0.402 \pm 0.012 \\
1.2\end{array}$ & $\begin{array}{c}0.773 \pm 0.024 \\
1.3\end{array}$ \\
\hline $\mathbf{F e}$ & $\bar{c}, \%$ & $0.327 \pm 0.016$ & $0.0548 \pm 0.0022$ & $0.764 \pm 0.078$ & $0.448 \pm 0.015$ & $0.454 \pm 0.010$ \\
\hline $\mathbf{C u}$ & $\begin{array}{l}s_{\mathrm{r}}, \% \\
\bar{c} / \mu \mathrm{g} \mathrm{g}^{-1}\end{array}$ & $\begin{array}{c}2.0 \\
10.9 \pm 1.4\end{array}$ & $\begin{array}{c}1.60 \\
8.7 \pm 2.0\end{array}$ & $\begin{array}{c}4.1 \\
54.2 \pm 6.7\end{array}$ & $\begin{array}{c}1.3 \\
14.0 \pm 0.8\end{array}$ & $\begin{array}{c}0.9 \\
14.5 \pm 1.3\end{array}$ \\
\hline $\mathbf{M n}$ & $\begin{array}{l}s_{\mathrm{r}}, \% \\
\bar{c} / \mu \mathrm{g}^{-1}\end{array}$ & $\begin{array}{c}5.0 \\
561 \pm 30\end{array}$ & $\begin{array}{c}1.0 \\
48.5 \pm 2.4\end{array}$ & $\begin{array}{c}4.9 \\
298 \pm 18\end{array}$ & $\begin{array}{c}2.1 \\
179 \pm 14\end{array}$ & $\begin{array}{c}3.5 \\
174 \pm 11\end{array}$ \\
\hline $\mathbf{Z n}$ & $\begin{array}{l}s_{\mathrm{r}}, \% \\
\bar{c} / \mu \mathrm{g} \mathrm{g} \mathrm{g}^{-1} \\
s_{\mathrm{r}}, \%\end{array}$ & $\begin{array}{c}2.16 \\
43.2 \pm 2.6 \\
2.44\end{array}$ & $\begin{array}{c}1.97 \\
147 \pm 15 \\
4.08\end{array}$ & $\begin{array}{c}2.5 \\
78.1 \pm 4.8 \\
0.9\end{array}$ & $\begin{array}{c}3.1 \\
35.7 \pm 0.8 \\
2.2\end{array}$ & $\begin{array}{l}2.5 \\
5.1 \pm 0.7 \\
5.8\end{array}$ \\
\hline
\end{tabular}

which excluded a significant difference between the variances at the 5 per cent significance level, the $t$-test was used to prove the null hypothesis $H_{0}$ :

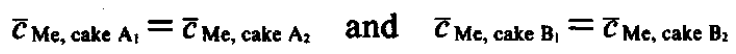

where the subscript $\mathrm{Me}$ refers to the element considered.

For all elements of cakes 1 and 2 from each batch $A$ and $\mathrm{B}$, the calculated $t$ values were always found to be smaller than the tabulated values; thus the null hypothesis was accepted in each case for all elements, indicating no significant difference (5\% significance level) between the mean analytical values of the two cakes from one batch. Consequently we may correctly assume that the metal concentration data of the cakes of each batch are homogeneous. The results of $\mathrm{Na}, \mathrm{K}$, $\mathrm{Ca}, \mathrm{Mg}, \mathrm{Fe}, \mathrm{Cu}, \mathrm{Mn}$ and $\mathrm{Zn}$ determination of the 
seized hashish batches are reported in Table 2 .

Once the homogeneity of the metal concentration analytical data has been proved within a cake and among cakes of a same batch, the variance analysis ${ }^{8}$ was employed to decide on the equality or the nonequality of the examined batches. The null hypothesis $\mathrm{H}_{0}$, in this case, was:

$\bar{c}_{\mathrm{Me}, \text { batch A }}=\bar{c}_{\mathrm{Me}, \text { batch B }}=\bar{c}_{\mathrm{Me}, \text { batch C }}=\bar{c}_{\mathrm{Me}, \text { batch D }}=\bar{c}_{\mathrm{Me} \text {, batch } \mathrm{E}}$

at the 5 per cent significance level.

Since the $F$ values calculated for all elements were found to be higher than the tabulated value, the null hypothesis was rejected and consequently we concluded that a significant difference existed among the mean values of the data relating to each element of the five batches considered. A test developed by Duncan ${ }^{8}$ was employed in order to find further statistical evidence of the diversity of the mean values of the data for each element in the five batches. The test refers to samples of equal size. As a result of the test, the conclusion was drawn that, at the 5 per cent significance level, the mean metal concentration values of all batches were statistically different in the cases of $\mathrm{Na}, \mathrm{Ca}, \mathrm{Cu}$ and $\mathrm{Zn}$, while they were not found statistically different in batches $D$ and $E$ in the cases of $F e$ and $M n$ as well as in batches $C$ and $E$ in the case of $K$ and in batches $B$ and $\mathrm{D}$ in the case of $\mathrm{Mg}$.

As far as the first aim of our work is concerned, we can maintain that, even in the case of a complex organic matrix as hashish, the "Carbonaceous Slurry" technique was found to be reliable, as previously verified in hay, pine needles, barley flour, maize flour, wheat flour, soybean, orchard leaves, bovine liver, oyster tissue samples. ${ }^{2-4}$ This fact confirms our opinion that the proposed method can be employed in the analysis of other complex organic matrices. In regard to the question of whether the equality of the seized hashish batches can be proved, once the analytical data homogeneity is demonstrated within a cake (relative standard deviation) and among the cakes of one batch $(t$-test), the variance analysis shows that it is possible to establish the equality or the non-equality of narcotics batches for sale on the street.

In the present work, the variance analysis proves clearly that batches A, B, C, D and E differ from one another.

\section{References}

1. T. T. Gorsuch, "Destruction of Organic Matter", Pergamon Press, Inc., New York (1970).

2. F. Fagioli, S. Landi, C. Locatelli and C. Bighi, Anal. Lett., 16(A4), 275 (1983).

3. F. Fagioli and S. Landi, Anal. Lett., 16(A17 \& 18), 1435 (1983).

4. F. Fagioli, C. Locatelli, S. Landi and C. Bighi, Atomic Spectrosc., in press.

5. A. Brandone, E. Marozzi and M. Montagna, Riv. Merceol., 23(III), 307 (1984).

6. “Analytical Methods for Atomic Absorption Spectrophotometry", The Perkin-Elmer Corp., Norwalk, Connecticut (1982).

7. I. Martinsen and F. J. Langmyhr, Anal. Chim. Acta, 135, 137 (1982).

8. J. S. Milton and J. O. Tsokos, "Statistical Methods in the Biological and Health Sciences", McGraw-Hill Book Company, New York (1983).

(Received November 16, 1985) (Accepted March 20, 1986) 